\title{
Violencia y Nuevo Testamento. Aporte exegético a una cuestión debatida
}

\author{
Xavier Alegre, \\ Facultad de Teología de Cataluña. \\ Centro de Reflexión Teológica, San Salvador.
}

\section{Introducción}

J. Moltunann seffalaba en su artículo "Dios y la revolución"1, que muchos abandonaban la Iglesia porque estaban convencidos de que sólo podían vivir su fe cristiana en solidaridad con los oprimidos. Algunos, incluso, llegaban a abandonar el cristianismo porque tenían la impresiơn de que éste había perdido su fuerza movilizadora de la historia, su capacidad de crear hombres y mujeres nuevos/as. Para ellos el cristianismo, con su rechazo global de la violencia (así interpretan muchos el Nuevo Testamento), se convertiria en un movimiento alienante y desmovilizador de las fuerzas populares. Y eso en un mundo profundamente injusto, que está claramente configurado por estructuras injustas que no dejan que las mayorias populares vivan dignamente $y$, a menudo, no permitan siquiera que vivan².

Pero si en la tradición más genuina de la fe cristiana se encuentra la experiencia del Exodo, es decir, la experiencia del Dios que libera al pueblo de Israel de la opresión del imperio egipcio, ¿podemos seguir pensando, sin matices, que la fe cristiana es desmovilizadora, porque defendería un pacifismo a ultranza? De hecho muy pronto los cristianos - como ya antes le habia ocurrido al mismo Jesuis- entraron en conflicto con los poderes estatales que los vieron como unos revolucionarios, en acto o en potencia, legando hasta a denigrarlos como "enemigos del género humano". Para ayudar a clarificar este punlo, el presente articulo se propone analizar el tema de la violencia en general, y de la violencia estatal en particular, en los escritos neolestamentarios, sobre todo en Pablo, Lucas-Hechos y Apocalipsis'. Me detendre, de modo particular, en las relaciones 
de los cristianos con el Estado (romano), pues los primeros cristianos se vieron confrontados con la violencia, precicamente en sus relaciones con el Estado romano. ¿Qué podemos saber, a partir de los textos neotestamentarios, sobre la actitud de los primeros cristianos frente a la violencia? ¿Tuvieron los primeros cristianos una actitud clara y homogenea frente a ella o hay que contar con un cierto pluralismo y evolución en este punwo?

El cristiano medio piensa, a menudo, que la actitud de Jesús frente a la violencia fue de rechazo total. Consecuentemente, la actitud de los escritos neotestamentarios sería también la del rechazo total de la violencia. Pero, les efectivamente asî? De hecho, hemos aprendido a descubrir el pluralismo del Nuevo Testamento en temas tan centrales como la cristología o la eclesiologí. ¿No ocurrirá lo mismo con el tema, menos central, de la violencia y de la actioud del cristiano frente al Estado? Por otro lado, ¿no forma parte la violencia, se quiera o no se quiera, de la experiencia de todo ser humano? De hecho, A. Salas empieza asi un artículo que lleva por título "Evangelio y violencia ayer y hoy". "La violencia en sf no es ni buena ni mala. Es simplemente necesaria. Viene exigida por la dinámica evolutiva que rige la andadura cósmica. Todo ser pugna, en efecto, por realizarse, luchando contra cuantos elementos dificultan su afán de superación. Tal lucha se hace dramática cuando est́ en juego la subsistencia. ¿Quién no recurre a la violencia si la juzga necesaria para conservar su vida? Tal es la ley que rige la evolución de las especies, pudiéndose afirmar que todo el proceso cósmico se basa en el dinamismo de la violencia" ${ }^{\text {"4 }}$. ¿Qué dice, pues, el Nuevo Testamento de la violencia y, más concretamente, de la relación del rristiano con las autoridades estatales?

Aparte de lo que el maestro Jesús habla dicho sobre la violencia, las comunidades cristianas primitivas se vieron confrontadas, de entrada, con un hecho que las obligó a revisar su actitud frente a la violencia y al Estado. Me refiero a la muerte de Jesús en la cruz. Es un hecho histórico innegable que Jesús murió víctima de la violencia $-y$ una violencia arroz, como era el suplicio de la cruz-, más concretamente, de la violencia estatal, que, por lo visto demasiado a menudo, sacrifica los intereses de la justicia y de los individuos a los "intereses del Estado"s. Jesús fue condenado a muerie por un procurador romano, Poncio Pilato, que quería preservar la Pax Romana. Y la sentencia fue ejeculada por soldados romanos. ¿Marcó este hecho, de manera importante, la actitud de los cristianos frente a la violencia y al Estado?

La respuesta, evidentemente, liene que ser positiva. Pero nos da sólo un aspecto importante de la experiencia de los primeros cristianos. Hay otro aspecto, también muy importante, que configuró también esencialmente la actiund cristiana frente al Estado, a pesar de la violencia estructural que, a menudo ejerció frente a los cristianos. Me refiero a lo que se ha denominado la Pax Romanat. El contexto vital en el cual los autores y las comunidades del Nuevo Testamento 
realizaron sus reflexiones sobre la violencia y la paz y sobre el Estado, fue el de la Pax Romana, es decir, el imperialismo romano que dominaba el mundo en el que se gesto el Nuevo Testamento y que comunicaba la convicción de que era una fuerza dominante a la cual no se podia resistir?. Si excepunamos a Pablo, los escritos neotestamentarios que vamos a ver están escritos después de la guerra judio, en la que la revolución armada fracaso y de la que los cristianos se distanciaron. Si la primera experiencia - la cruz- podía llevar a los primeros cristianos a tomar una actitud distante y critica frente al Estado y su violencia estructural -predicar a un crucificado por el poder estatal, no sólo podía ser visto como un escándalo para los judíos y una necedad para los griegos ( $c f$. 1Co 1, 23), sino también como factor de resistencia contra el poder romano, en un mundo que era dominado por los romanos, entre otros medios, gracias a las crucifixiones de los rebeldes políticos - la segunda (me refiero a la Pax romana), en cambio, obligaba a ser "realista" en un mundo claramente dominado por los romanos y a procurar "adaptarse" y aprovecharse de los medios que la Pax romara ponfa a disposición de los misioneros cristianos y de las comunidades en general. Los testimonios del Nuevo Testamento se mueven, como vamos a ver, dentro del marco indicado por estos dos polos - distancia crítica-adaptacion-, destacendo más uno u otro aspecto según el talante y las circunstancias que viven el autor del escrito y la comunidad.

\section{La distencin critica}

El exponente más úpico de esta actitud lo encontramos en el libro del Apocalipsis. Dentro de la más genuina tradición apocalíptica, la obra quiere ser un "escrito de resistencia" frente a la autoridad civil —en este caso Roma-. que estŕ persiguiendo a la comunidad cristiana. Como la persecución ha producido ya algunos mártires (Cf. Ap $6,9-11 ; 17,6 ; 18,24)$ y la amenaza del poder romano, que utiliza la violencia estatal para imponer sus valores, conlleva el peligro de acabar con la resistencia de los cristianos, urge escribir una obra que, por un lado, muestre claramente quién es el verdadero Seftor de la historia - frente a las pretensiones de los "seffores" (emperadores) romanos, en concreto, Domiciano - y, por otro, anime a los miembros de la comunidad a mantenerse firmes en los valores evangélicos ( $c f$. Ap 13, 7-10), Lomando conciencia de la poca consistencia y caducidad del imperio romano y de sus logros (cf. Ap 17-18).

En todo caso, las circunstancias que viven el autor y su comunidad y, sobre todo, la finalidad del escrito, explican que la actitud del Apocalipsis frente al poder romano sea sumamente negativa. De hecho, todo el escrito quiere ejemplificer, tomando como exponente concreto el caso del imperio romano, cómo todo poder que no respeta el sefiorío de Dios y de su Mesías, está condenado al fracaso, por más que ahora, aparentemente, triunfe. Para ello se sirve, fundamentalmente, de una visión esquematizada y global de la historia universal, tal 
como puede leerse a la luz del Antiguo Testamento (en esto sigue a Daniel). En ella se ve cómo la historia terrena es el escenario de una lucha a muerte entre dos poderes: el del mal, simbolizado por Satanás, y el del bien, encarnado por Dios y por su Mesías ( $f$. Ap 12). El mal utiliza su poder real en este mundo para seducir a los seres humanos, violentando y aniquilando a todos los que se oponen a su dominio y pretenden defender otros valores distintos de los encarnados por el ( $c f$. Ap 13, 15-17). La historia enseffa que, por lo menos aparentemente, triunfa siempre. Y de hecho ahora, con Roma o con Espanta a partir del descubrimiento de América (o con Estados Unidos hoy), estấ triunfando. Pero una visión teológica de la historia muestra también que, a la larga, siempre acaba fracasando. Porque el verdadero Seflor de la historia es Dios. Esto es lo que muestra el Apocalipsis, sobre todo con ayuda de la estructura concéntrica que el autor da a su obra ${ }^{10}$, dominada por los septenarios, símbolos de la fidelidad de Dios a la Alianza ${ }^{11}$, y con el quinto septenario ( $\left.c f .19,9-22,5\right)$, en el que se describe la victoria definitiva de Dios y la aprición del cielo nuevo y de la tierra nueva, en la que "no habrá ya muerte ni habrá llanto, ni gritos ni fatigas, porque el mundo viejo ha pasado" (Ap 21, 4).

Pero el autor se sirve también de otro medio importante para que el cristiano aprenda a distanciarse críticamente del imperio y de su poder amenazante. Por medio de símbolos, muy significativos para una comunidad cristiana de raíces veterotestamentarias, identifica claramente al imperio romano con el mal y describe anticipadamente, para gozo de la comunidad perseguida, el fracaso de Roma y su caida en un tiempo que, en principio, no puede estar muy lejano. Para él, el dragón (Satán) ha entablado una lucha a muerte con la mujer adornada de doce estrellas (la nueva humanidad), madre del hijo varon (el Meslas Jesús) y contra el resto de sus hijos (los cristianos) que están aquí en el mundo ( $f$. Ap 12, 3-5; 13-17). Con esta finalidad ha entregado su poder a la bestia del mar (probablemente se refiere al poder político de Roma: (cf. Ap 13, 1-10), al servicio de la cual, la bestia de la tierra (probablemente el paganismo totalitario) juega el papel de falso profeta (cf. Ap 13, 11-18). La bestia se presenta con pretensiones totalitarias y, además de hacer exterminar a cuantos no adoran su imagen ( $c f$. Ap 13, 15), "hace que todos, pequeffos y grandes, ricos y pobres, libres y esclavos, se hagan una marca en la mano derecha o en la frente, y que nadie pueda comprar nada ni vender, sino el que lleve la marca con el nombre de la Bestia o con la cifra de su nombre" (Ap 13, 16-17). Si a continuación, en Apocalipsis 13, 18, el autor nos dice que el número de la bestia es el 666 y que es la cifra de un hombre, queda claro para el leclor de la época, iniciado en el lenguaje críptico apocalíptico, que se trata del emperador romano Domiciano, el Nero redivivus, que representa aquí el poder violento e injusto del imperio romano ${ }^{12}$. En este sentido, el capítulo 13 del Apocalipsis es la crítica más dura frente al Estado - un Estado que usa la violencia para imponer, injustamente, su poder y sus valores - que encontramos en el Nuevo Testamento. Siendo esto 
ast, ya no nos sorprendera que para el autor del Apocalipsis, Roma sea la gran ramera, la Babilonia odiada de que habla el Antiguo Testamento (cf. Ap 17-18), destinada al juicio condenatorio de Dios con todos sus secuaces (cf. Ap 19;20, 7-12). Por eso, el anuncio y descripción de su calda en el futuro intramundano es descrita con particular detalle - iy alegría no disimulada! - en el capítulo 18.

El capítulo comienza con el grilo de victoria que anuncia la caída de Roma: "|Cay6, cay6 la Gran Babilonia! Se ha convertido en morada de demonios, en guarida de loda clase de espírilus inmundos, en guarida de toda clase de aves inmundas y detestables" (Ap 18, 2). Pero a continuación, para lección de los cristianos, el autor tiene interts en subrayar la causa de su calda: no es por el hecho de ser poderosa que estí condenada a la calda, sino por el hecho de que, con sus falsos valores -por el orgullo que le hace prescindir de Dios y de su ley ("pues dice en su corazón: Estoy sentada como reina, y no soy viuda y no he de conocer el llanton: Ap 18, 5), por el consumo y lujo desenfrenado con los que ha llevado a muchos mercaderes y reyes de la tierra a prostituirse ${ }^{13}$ con ella (cf. Ap 18, 3.9.23) y por la violencia con que aniquiló a todos los que fueron criticos con su dominio injusto (cf. Ap 18, 24: "En ella fue hallada la sangre de los profetas y de los santos y de todos los degollados sobre la tierra")- ha cafdo en el pecado y ha hecho pecar a otros ("porque sus pecados se han amontonado hasta el cielo y Dios se ha acordado de sus iniquidades": Ap 18, 5; cf. tambiên 18, 8: "Por eso, en un solo dla llegarán sus plagas: peste, llanto y hambre, y serd consumida por el fuego. Porque poderoso es el Setior Dios que la ha condenado"). Por eso, el autor, que sabe que los valores del imperio ejercen también su poder seductor sobre sus cristianos y cristianas, tiene interés por subrayar aqui a su comunidad que es conveniente que se distancie de Roma y de sus valores: "Salid de ella, pueblo mio, no sea que se hagan cómplices de sus pecados y les alcancen sus plagas" (Ap 18, 4b) ${ }^{14}$. Pues Dios vendra pronto ( $c f$. Ap 1, 3.7; 22, 10.12.20) en la persona de su Hijo para restablecer definitivamente su reino. Entonces, Babilonia, como acabamos de ver, será aniquilada, la bestia será arrojada al estanque de fuego con todos sus ejércilos (cf. 19, 1121) y Satanás irá a reunirse con ella (cf. 20,7-10).

Lo que acabamos de ver nos muestra hasta que punto el Apocalipsis toma una actitud claramente distante y de critica frente al Estado concreto que le ha locado vivir, que es el imperio romano. La violencia sufrida, la experiencia del Cordero degollado y de los crisitanos martirizados 0 , al menos, perseguidos, lo ha llevado a una actitud sumamente critica frente al poder concreto del Estado, que él experimenta como absolutamente injusto y violento. Y ello no lo considera como un momento anecdotico, fruto de la locura de un gobernante concreto, sino que cree que éste puede ser un peligro real de todo poder político y por esto tiene interes en advertir a sus cristianos de los peligros que el poder político, económico, social y religioso comportan, cuando no se dejan marcar, en su misma esencia, por los principios cristianos que el autor ha descubierto en el 
Antiguo Testamento y en Jesús de Nazaret. De los dos polos que según decla al comienzo, configuran la experiencia crisliana en sus relaciones con el poder político, el Apocalipsis representa claramente la postura crítica frente al Estado.

Para el autor del Apocalipsis, el único que tiene verdaderamente poder es Dios, un poder que ha sido conferido al Cordero degollado. Ninguna instancia humana tiene, por tanto, auténtico poder, aunque a veces lo parezca, pues utiliza la violencia, a veces de manera muy solapada ("nadie puede comprar ni vender" leiamos en Apocalipsis 13, 17) para imponerse. Por eso, el autor es crítico frente a la violencia del Estado romano. Y, a la vez, afirma que ante este abuso de poder, Dios, Seffor de la historia, utilizara la violencia, un día no lejano, para restablecer la justicia. Pues para él, sólo Dios puede restablecer, con su poder, la paz y la justicia. En este sentido, el autor no propugna una violencia física, armada, contra Roma. De hecho, sabe que no tendria futuro. Pero con su violencia verbal está bastante alejado de lo que leemos en el Sermón de la montafia (cf. Mt 5-7) o de Lucas en general. Pues no parece confiar en que el amor consiga acabar con la violencia estructural que es la causa de su persecución. Con todo, no propone lomarse la justicia por su mano, sino que deja la venganza a Dios (cf. Ap 11, 17-18; 14, 6-13; 16-18).

Pero no es ésta la única postura que encontramos en el cristianismo primitivo, sobre todo antes de la persecución de Domiciano, que es el ambiente que refleja el Apocalipsis. Hay un autor que refleja, más bien, la otra postura, la del aprecio y acomodación al poder estatal romano. Me refiero a Lucas.

\section{La valoración positiva}

Al empezar a desarrollar la actitud de Lucas frente al Estado romano (tanto en el Evangelio como en Hechos), Wengst enjuicia así la postura del tercer evangelista: "En Lucas se encuentra una manera de percibir la Pax romane que es totalmente distinta de la de Jesús y Pablo. Aquf no se encuentra prácticamente ninguna afirmación negativa sobre Roma y sus representantes; más bien son presentados con una luz francamente favorable"15. Después de lo que acabamos de ver en el Apocalipsis, no puede menos de sorprendernos esta afirmación. Pero de hecho, responde a lo que reflejan los escritos lucanos, como subraya cambién R. F. O'Toole ${ }^{16}$. Por eso subraya Lucas que los cristianos son unos buenos ciudadanos que no violan las leyes romanas ${ }^{17}$ y tienen buenas relaciones con los romanos ${ }^{18}$. Si en alguna ocasión sufren violencia, ello no es culpa de las autoridades romanas, sino de los adversarios de los cristianos (sobre todo los judios), que actúan de mala fe y manipulan a las autoridades romanas ${ }^{19}$.

Efectivamente, un breve repaso de los datos que aporta la obra lucana, confirma la tesis de Wengst. En primer lugar, llama la atención que en la obra lucana aparecen, a menudo, soldados romanos que son presentados con una luz positiva, tanto por las buenas relaciones que mantiene con los judíos y, en 
Hechos, con los cristianos, como por su disposiciớn a la fe. Ejemplos clásicos serfan los centuriones de Cafarnaum (cf. Lc 7, 1-10) y el cenurión Comelio en Cesarea ( $f$. Hch 10), el primer pagano convertido ${ }^{20}$. En la misma linea vernos que Lucas presenta unos soldados que se acercan a Juan Bautista y reciben la recomendación, cuando preguntan, qué es lo que deben hacer. "No hagan extorsión a nadie, no hagan denuncias falsas, y conténtense con su soldada" (Lc $3,14)$, lo cual significa que, en contra de lo que veremos después en muchos de los autores cristianos de la etapa inmediatamente posterior, Lucas no ve como incompatible el ser soldado (romano) y el ser hombre creyente ${ }^{21}$. En todo caso, no les exige que dejen el servicio militar. Y si comparamos la actuación de los soldados romanos en la pasión de Jesús tal como los presenta Lucas, con la que presenta Marcos, veremos que los soldados romanos en Lucas han perdido los tonos negativos que tienen en los otros evangelios, pues solo aparecen cuando ye Jesis está clavado en la cruz, participando en la burla de los demás, cuando le ofrecen vinagre y le dicen a Jesús que baje de la cruz y se salve. Y cuando muere, es el centurión romano el que, como Pilatos antes, acentía la inocencia de Jesuis?.

Tambien las autoridades romanas, representadas por Pilatos en Lucas o por diversos procuradores y tribunos en Hechos, son presentados por Lucas con una lue más bien positiva. Esto vale tanto para el proceso de Jesús ante Pilatos (Luces tiene interks en subrayar que Pilatos declara por tres veces la inocencia de Jesís ( $c f$. Lc 23, 4.14-15.22), y que su condena no es culpa de Pilatos, sino de los responsables judíos), como para los distintos procesos y problemas que tuvo que sufrir Pablo por culpa de los judios ${ }^{22}$. Pues Hechos destaca que los oficiales romanos tratan bien a los cristianos y los protegen, a menudo, de las asechanzas de los judfos ${ }^{24}$.

De todos mados, Lucas no es un ingenuo y sabe muy bien que puede existir, de becho, el conflicto violento con el Estado. Por ello, menciona la flagelación de Pablo por parte de las autoridades romanas en Filipos ( $c f$. Hch 16, 22; pero subrayando que no se escapan de la prisión a pesar del terremoto: $c f$. Hch 16, 26-28). Pero en este caso indica, también, que Pablo apela a su ciudadanía romana y pide satisfacción por ello.

Finalmente, hay otro factor - lo trataré muy brevemente, pues se refiere más bien a Jesuís de Nazaret, cuya actitud frente a la violencia no forma parte de lo tratsdo en este artículo - que configura también la actitud que, según Lucas, el cristiano debe tener frente a la violencia. Se trata de uno de los rasgos más caracteristicos de la figura de Jesús en Lucas: su bondad y misericordia. En ello, Jesis es un reflejo fiel de la bondad y misericordia de Dios. Una bondad y una misericordia que llevan a Jesús hasta a amar a los enemigos, no solo con palabras ( $c f$. Lc 6, 27-31), sino también con hechos, como lo muestra incluso en los momentos conflictivos del prendimiento, cuando cura al siervo que ha 
venido a prenderie (cf. Le 22, 51), y de la muerte, cuando pide al Padre "perdónalos, porque no saben lo que hacen" (Lc 23, 34)2.

En este sentido, me parece que Lucas es el autor del Nuevo Testamento que presenta una actitud más conciliadora frente a la violencia estatal, sefialando que la palabra y el ejemplo del Maestro no perniten al cristiano responder a la violencia con la violencia - aparte de que, para él, enfrentarse violentamente a Roma seria, sin duda, una insensalcz condenada al fracaso y que comportarla un sufrimiento aún mayor para muchos.

Con codo, Lucas no llega al extremo de adaptación que encontramos en Clemente Romano"s , quien llega a decir: "Tú, Seftor, les has dado" (a nuestros gobernantes) "por tu fuerza sublime e indescriptible poder la capacidad de dominar, para que nosotros reconozcamos la gloria y el honor que tí les has dado, a fin de que les obedezcamos, con lo cual nosotros no nos oponemos en nada a tu voluntad" $(61,1)$.

\section{Tensión escatologica}

La tercera postura que quiero presentar aquf es la de Pablo. Aunque el Apóstol está más cerca de Lucas que del Apocalipsis en esta cuestión que estamos tratando, sin embargo, me parece que representa una postura más bien intermedia entre ambos, sobre todo si leemos Romanos 13, 1-7 en el marco de las cartas que son ciertamente auténticas de Pablo².

\subsection{Los textos críticos}

En primer lugar, encontramos una serie de textos paulinos que revelan una cierta distancia crítica del Apóstol frente a las autoridades y el poder romano. Dos me parecen las razones principales que llevarian a Pablo a tomar esta actitud critica: (a) por un lado, su experiencia historica con dichas autoridades; y (b) por otro, la reserva (Vorbehalt) cscatológica que es propia de su teología.

\section{(a) La experiencia historica}

Por las carlas de Pablo sabemos que el Apostol tuvo que sufrir en carne propia la actitud persecutoria e injusta de los poderes romanos (y de sus aliados). Procesos, encarcelamientos, azotes y persecuciones en general acompanaron al Apóstol a lo largo de su actividad misionera, no sólo de parte de los judros, sino también de las autoridades romanas (cf. 1Co 11, 25-26.32-33; $c f$. también 2Co 6, 5) $2 \mathrm{n}$. De las cartas se deduce claramente que Pablo experimentó en came propia la violencia, también por parte de las autoridades estatales, y una violencia que él considera injusta.

El motivo por el cual Pablo tuvo que sufrir fue, simplemente - por lo menos asf lo interpreta é- por el hecho de ser cristiano ${ }^{29}$. Ello implica que las auto- 
ridades romanas verian en la predicación de Pablo -como había ocurrido ya antes con la de Jesús - una perturbación del orden público ${ }^{30}$. Para ellas sin duda, Pablo ponia en peligro la Pax romana. En este sentido, Pablo tendría conciencia, por tanto, de que el Estado romano era un perseguidor potencial -y en ocasiones, actua- de su persona y de las comunidades cristianas".

Por eso, no tiene que sorpendernos que encontremos en Pablo una serie de textos que reflejan una distancia crfíca frente a Roma (que, para él, era la encarnación del poder estatal):

- Es esceptico frente al lema "Paz y seguridad" (cf. 1Te 5, 3) que sus lectores asociarlan necesariamente con una pretensión propia de la Pax romana ${ }^{32}$, pues para Pablo la salvación y el bienestar humano no están garantizados $\rightarrow$ ni pueden venir de- por el mero progreso prometido por el Estado romano"3. Más aún, si leemos el texto en su contexto (cf. 1Te 5, 1-11), vemos que Pablo sioia en la esfera de las tinieblas la $P$ ax romana que, aparentemente, da seguridad a los cristianos".

- Es crítico frente a los poderes y senores de este mundo, que crucificaron a Jesis ( $f$. 1Co 2,8$)^{33}$, hasta el punto de que, según él, en el momento final, todo principedo, dominio y poder sera destituido ( $c f$. 1Co 15, 24-26)

- Aunque no cuestiona, en principio, el poder judicial romano en 1Corintios 6, 1-8; sin embargo, la manera como recomienda a los cristianos de Corinto que no vayan a los tribunales civiles, muestra, al menos indirectamente, que Pablo no tiene especial confianza en ellos ${ }^{37}$.

- Si en Filipenses 1, 20ss teme que, a pesar de ser inocente, su proceso ante las autoridades romanas pueda acabar con la condena y la muerte, ello implica que pera Pablo la autoridad judicial romana no siempre ofrece la garantía de impertir justicia

- En todo caso, es claramente contestatario frente a las autoridades romanas. Pues si a pesar de ser perseguido, azotado, encarcelado, etc., por ellas, persiste en su empefto y acturación misioneras, que lo llevan al conflicto con dichas autoridades, es que Pablo no acepta, sin más, su autoridad ${ }^{36}$. Por lo menos aquf no las vería como "servidoras de Dios" y como instrumento de su voluntad en el mundo.

Por todo ello, me parece que Pablo, dada su experiencia personal histórica, no podria sentirse muy identificado con la Pax romana y con las autoridades romanas.

\section{(b) El reparo escarológico}

La tensión escatologica entre el ya y el todavía no, que, según Pablo, es inherente a toda realización humana, pondría también sordina a las pretensiones 
del Estado romano y configuraria, por tanto, también, la visión que Pablo tendria de la autoridad civil.

Para Pablo, por otro lado, el cristiano debe tener conciencia, ante todo, de que su derecho de ciudadanía está en el cielo (cf. Flp 3,20)39. Ello no implica, ciertamente, que la autoridad civil -como otras realizaciones humanas- no tenga su propio valor ${ }^{40}$. Pero el trasfondo apocalíptico del pensamiento paulino, que comporta la convicción de que este eón, marcado por el pecado, está condenado a la muerte ${ }^{41}$, me parece que no permitiría a Pablo tomar una actitud demasiado favorable, por lo menos de principio, frente a las autoridades ro$\operatorname{manas}^{2}$.

\section{2. ¿Texto favorable al Estado?}

Pero hay un texto paulino que, a menudo, se ha aducido -y asl lo dernuestra la historia del influjo del texio ${ }^{43}$ - para sostener la actilud más bien "adaptada" de Pablo frente a las autoridades civiles. Me refiero a Romanos 13, 1-7.

Es innegable que este texto se desmarca de otros textos auténticos de Pablo. Por eso, se ha pretendido relativizarlo de distintas maneras: o bien negando que Pablo sea su aulor $r^{\text {H4 }}$ o bien procurando devaluar su significado, en el sentido de que no sería un texto especialmente paulino45. Pero tampoco esto parece ser una buena exégesis del texto ${ }^{46}$.

Esto supuesto, ¿qué pretende, pues, Pablo, con este texto?

Como no puedo hacer aquí una exégesis detallada del tex10 ${ }^{47}$, me voy a limitar a unas cuantas afirmaciones sobre el mismo que me parecen fundamentales:

(1) Pablo recomienda aquí al cristiano(a) una lealtad, que podriamos llamar "fundamental", frente al poder civil ( $c f . \mathrm{Rm} 13,1 \mathrm{la})$. Esto me aparece algo evidente que ha sido aceptado sin dificultad por los especialistas.

(2) Lo problemático del texto empieza en el momento en que se analiza la argumentación con la cual Pablo pretende fundamentar su recomendación a la comunidad. Pues a menudo ha sido manipulada, como indica Schrage"t, "en el sentido de una actitud de sometimiento servil y nada crítica y de una fundamentación boblica al servicio de una dignidad y metafísica del Estado embellecidas religiosamente".

(3) Pablo no pretende aqu dar una reflexión metafísica - una doctrinasobre la esencia y el valor de la autoridad civil. Se trata, más bien, de un texto parenético - de corte claramente funcional ${ }^{49}$ - que se limita a recomendar, pragmáticamente, la lealtad del cristiano Irente a las autoridades civiles ${ }^{50}$. Un Estado pagano que, como he dicho antes, tiene un poder tan bien cimentado que, por lo menos cuando Pablo escribe, no puede ser subvertido. 
(4) Ciertamente, ayudaría a una exégesis adecuada del texto el que pudiéramos conocer las razones concretas - sean de la situación que Pablo está viviendo personalmente, sean de la comunidad romana a la que Pablo dirige esta exhortación- que podrán haber motivado, concretamente, este texto de Pablo. Pero en el estado actual de la investigación no podemos responder positivamente a esta pregunta ${ }^{31}$. Con todo, personalmente pienso que Pablo estaría interesado, de entrada, en unas buenas relaciones, en lo posible, con las autoridades del Estado, sobre todo en el momento en que desea visitar a la comunidad de la capital (y terne los peligros que le van a acechar en Jerusalén por parte de los judros: (cf. Rm 15, 30-32) para, desde allí, iniciar un nuevo campo misionero en occidente (Espafia)(cf. 15, 28). Por otro lado, una oposición al Estado está -en el momento en que escribe Pablo - condenada al fracaso y sólo redundaría en perjuicio del cristianismo naciente, sobre lodo si no se puede aprovechar de los privilegios de la religio licira.

(5) La única pista sólida para poder interpretar adecuadamente Romanos 13, 1-7 nos la ofrece el contexto. Un contexto, por otro lado, que resulta muy significativo para el tema de la actitud del cristiano frente a la violencia, que es lo que nos interesa especialmente aquí.

\subsection{El contexto de Romanos $13,1-7$}

Aparte del contexto amplio, en el cual hay que situar el texto -una parenesis que abarca desde 12, 1 hasta 15, 13-, me parece decisivo, para comprender el significado de Romanos 13, 1-7, tener bien presente el contexto inmediato en el cual Pablo ha situado el texto.

Ya la introducción a todo el fragmento me parece fundamental para comprender el punto de mira con que Pablo va a desarrollar las exhortaciones que contiene este fragmento. Pues en Romanos 12, 1-2 leemos: "Les exhorto, pues, hermanos, por la misericordia de Dios, a que ofrezcan sus cuerpos como una victima viva, santa, agradable a Dios: tal será su culto espiritual. Y no se acomoden al mundo presente, antes bien transर́ómense mediante la renovación de su mente, de forma que puedan distinguir cuál es la voluntad de Dios: lo bueno, lo agradable, lo perfecto".

Dos cosas me parece importante notar aqui. En primer lugar, que Pablo desea que la praxis cristiana sea como el culto espiritual que el creyente ofrece a Dios (cf. v. 1). Y, en segundo lugar, que esta praxis no se acomode al modelo de este mundo, sino que busque la voluntad de Dios, la perfección (cf. v. 2). No son, pues, reflexiones metafísicas o consideraciones éticas generales las que Pablo ofrece aqui, sino una invitación a vivir la perfección cristiana, una perfección que, como ha indicado ya antes en la misma carta, brota de la experiencia de la justificación gratuita por parte de Dios (cf. 1, 16-31) y del amor, también gratuito y humanamente desconcertante, de Dios, un amor que el Es- 
pfritu Santo ha derramado en nuestros corazones ( $c f . \operatorname{Rm~5,~5).~Solo~desde~esta~}$ experiencia fundamental se puede comprender que Pablo diga en Romanos 13, 8-10, a continuación del texto que intentamos ahora comprender, y formando inclusión con el texto que le precede inmediatamente ( $f$. $R m 12,17-21)$, que la perfección y plenitud de la Ley de Dios consiste en amar al projimo como a sí mismo ( $f$. Rm 13, 9 en el contexto de 13, 8-10). En el fondo, todo el hilo conductor de la reflexión de Pablo en Romanos $12-13^{52}$ es el desarrollo, con ejemplos concretos, de una praxis cristiana que esté en consonancia con la revelación, en Cristo, del amor desconcertante y gratuito de Dios, una revelación que debe llevar al cristiano a plasmar en su vida, personal y colectivamente, una manera de actuar que sea signo en el mundo de lo que P. Ricoeur ha denominado la "lógica de la gratuidad" (en contraposición a la lógica de la equivalencia que parece configurar nuestro mundos3). Pues para Pablo sólo esta "l6gica" será capaz de crear entre los cristianos una auténtica convivencia "en paz", superando el flagelo deshumanizante de la violencia, no con un simple pacifismo, sino con un amor activo y desarmante como el que él propone en Romanos 12, 17-21.

Desde esta perspectiva podemos comprender mejor cómo Pablo estructura aquf sus reflexiones. Si el amor de Dios, tal como se ha hecho palpable en Jesús, ha de configurar toda la vida cristiana, se comprende que la violencia quede excluida, en principio, de la vida y de la convivencia comunitaria del cristiano. Por ello, Pablo empieza a hablar de la vida de la comunidad utilizando la imagen del cuerpo, pues ello le sirve para ilustrar el que cada miembro de la comunidad debe descubrir su papel - su función- según el don concreto que haya recibido de Dios $(c f .12,3-9)^{\text {s4 }}$.

A continuación -y desarrollando más el motivo de la humildad, que aparecí ya en 12, 3-8 como condición de posibilidad de una convivencia cristiana en el amor que no violente al projimo (el orgullo es una manera muy sutil de violentar al projimo y fuente de tensiones entre los seres humanos)-. Pablo explica cómo debe ser el amor cristiano, un amor que, por otro lado, sea capaz, incluso, de superar el mal y la injusticia, que uno pueda sufrir por parte de los demás ( $f f .13,9-21$, sobre todo los vv. 9 y 21), con el bien.

En este contexto, que culmina con la afirmación de Pablo en 12,21, de que el cristiano debe vencer el mal, no con un mal mayor o con la violencia, sino con el bien, y que prepara la afimación, en 13,9, de que debe amar al projimo como a sí mismo, hay que sibuar las reflexiones paulinas sobre el esiado en Romanos 13, 1-7 y sobre la violencia en general. Es la manera como Pablo concreta la regla de oro que proclamo Jesús según Mateo 7, 12 y que debe llevar hasta a amar al enemigo ( $f$. Lc 6, 27-31 y el texto paralelo de Mit 5, 43-48).

Después de lo que acabo de decir, creo que se pueden resumir as las conclusiones que me parece que se siguen del contexto inmediato y amplio (toda la 
carta a los Romanos) en que Pablo ha situado Romanos 13m 1-7:

- La experiencia del amor sorpendente y graluito de Dios es un don que se convierte para el cristiano en tarea: ser signo en el mundo de esta realidad amorosa de Dios. Por ello, todo cristiano debe ser signo en el mundo de esta paz de Dios - que es mucho más que la simple renuncia a la violencia- que, en la realidad escatológica, en la cual vive el cristiano, es don y tarea a la vez ${ }^{35}$.

— La fe en el Crucificado - ien la cruz Dios no respondió a la violencia humana con otra violencia! - invita al cristiano a renunciar a la violencia y al poder agresivo, procurando, al contrario, superar el odio con el amor (cf. 1 Te 5, $15)^{36}$.

- Desde la experiencia de la comunidad cristiana, en la que se han superado las barreras nacionales, sociales e, incluso, religiosas ( $c f$. Ga 3, 28), la comunidad es invitada a ser un espacio en el cual la violencia quede interrumpida, más aún, la comunidad es invitada a ser el lugar más próximo de una praxis cristiana de la paz ${ }^{57}$.

- Para ello, el cristiano debe tomar la iniciativa, tanto a nivel individual, como comunitario (lo cual incluye también el poder civil), rompiendo, de una vez, el círculo vicioso de la violencia ( $c f .1 \mathrm{Co} 4,12$ y $\mathrm{Rm} 12,14$ ), hasta el punto de renunciar a la venganza, procurando vencer el mal con el bien: "Bendigan a los que les persiguen, no maldigan. (...) Sin devolver a nadie mal por mal; procurando el bien ante todos los hombres; en lo posible, y en cuanto de ustedes dependa, en paz con todos los hombres; no tomando la justicia por cuenta suya, queridos míos, dejen lugar a la Cólera, pues dice la Escritura: Mia es la venganza; yo daré el pago merecido, dice el Sefior. Antes al contrario: si tu enemigo tiene hambre, dale de comer; y si tiene sed, dale de beber, haciéndolo asf, amontonarás ascuas sobre su cabeza. No te dejes vencer por el mal; antes bien, vence al mal con el bien" $(R m 12,14.17-21)$.

- Pero ello no significa que el principio cristiano sea la no violencia a cualquier precio. El principio irrenunciable no es la no-violencia, sino el amor. Pues en Romanos 12, 18, Pablo, que no es nada ingenuo, ha dicho que el cristiano debe procurar por todos los medios la paz, pero notando "en cuanto dependa de ustedes"su. Pablo sabe muy bien que la paz no depende solo de la buena voluntad de uno. Pero aqui no se plantea - y no desarrolla, por tantohasta qué punto puede ser legítino utilizar la violencia para evitar, por ejemplo, un mal mayor.

- Por eso, Pablo no diviniza al Estado, sino al amor. Pues está convencido de que la manera cómo el cristiano puede transformar el mundo - y el Estado (romano)- es el amor. Para él, el Estado no es una "realidad última" ni tiene carta blanca en sus decisiones. Por eso sehala también en Romanos 13, 1-7, que el Estado ha recibido el encargo de estar al servicio de la justicia, fomentando el 
bien y castigando el mal. Sólo Dios puede determinar lo que es el bien y lo que es el mal. Por eso nola, con razón, Wilckens: "Lo que sin duda es ciero es que Pablo en Romanos 13, 3-4 no separa el bien y el mal, como si estos consistieran en una 'honradez' externa 'y lo contrario de ella', en el sentido de una justicia civil, del sentido obligatorio que el bien y el mal tienen para los cristianos en el texto precedente $(12,2.9 .17 .21)$. Tal como muestra sobre todo la transición de 13, 7 a 13, 8-10, el bien está definido, en cuanto a su contenido, de modo decisivo, por el amor, mientras que el mal, consecuentemente, por lo contrario al amor." ${ }^{\text {ng? }}$.

- La conciencia de estar en los úllimos tiempos, que aparece inmediatamente después de los textos que he comentado ( $c f$. $\operatorname{Rm} 13,11-14)^{60}$, relativiza el papel de las autoridades civiles y, consecuentemente, de la oposición-resistencia frente a ellas (como relativiza otras realidades humanas: $c f$. 1Co 7, 16ss). Pues lo que de veras interesa al cristiano -y esto es 10 que Pablo quiere recomendarle, para que su praxis sea un auléntico culto a Dios-es que se desnude de las obras de las tinieblas y se revista de las armas de la luz (cf. Rm 12, 17 21). Pues por algo el amor, aparentemente impotente, del Crucificado se ha mostrado como más fuerte, incluso, que la muerte. El cristiano debe empezar ad intra renunciando a la violencia y siendo auténtico creador de paz (cf. 1Te 5, 13; Rm 12, 18; 2Co 13, 11), para que pueda serlo también ad extra.

\section{Conclusion}

Despuês de lo que acabamos de ver en Pablo, creo que ya podernos destacar, a modo de conclusión, lo que yo denominaría el "aire de familia" o la experiencia fundamental que da unidad a la pluralidad de los texlos neotestamentarios. Permítanme que lo indique con unos breves enunciados.

(1) Lo que caracteriza al cristiano no es, propiamente, la no-violencia, sino la paz. Una paz que se basa en el amor y en la justicia; pero una justicia que no es entendida como justicia equitativa, en el sentido griego, sino desde su trasfondo veterotestamentario: como una justicia que brota del amor gratuito de Dios, que quiere que todos los seres humanos se salven y vivan una vida digna verdaderamente de este nombre.

(2) Pero la paz no está, sin más, al alcance de los seres humanos. El ser humano concreto es un ser descontento, lleno de conflictos, violento a menudo. Nuestra vida está configurada también por realidades deshumanizantes como la ira, el orgullo, el ansia de tener y de dominar cada vez más. La Biblia llama a eso pecado y nos recuerda - para que seamos realistas - que todos somos pecadores (cf. Rm 1, 18-20). Pues o bien queremos ser como dioses, o bien estamos dispuestos a idolizar realidades tan finitas como el consumo, el dinero, el poder, lo cual nos lleva, con facilidad, a ejercer violencia contra el projimo en nuestras relaciones interhumanas. Aparentemente nos encontramos en un calle- 
jón sin salida. La violencia ha sido hasta ahora una realidad permanente en nuestro mundo y no somos capaces de construir una paz que merezca de veras este nombre (llamar paz, por ejemplo, a la violencia institucionalizada que Estados Unidos ha querido imponer hasta ahora en El Salvador, es de un cinismo impresionante).

(3) Pero esa no es toda la realidad humana ni la última palabra sobre ella. Pues Dios, que es un "Dios de la paz" (1Co 14, 33; Rm 15, 33; 16, 22; Flp 1, 2; Col 1, 20), ha intervenido salvíficamente en la historia del mundo, haciendo real y posible la paz, que es, asi, un don de Dios en Cristo "nuestra paz" (Ef 2, 14). Pues Jesús murió en la cruz para acabar definitivamente con la violencia y el egoísmo humano, reconciliando al ser humano con Dios y con los demás (cf. 2Co 5, 18-21). Por eso, quien quiera construir la paz, oponiéndose a la violencia individual y estructural, lo debe hacer como quien se sabe, a su vez, perdonado, justificado gratuitamente por Dios.

(4) El cristiano está invitado, personal y comunitariamente, a construir la paz, de modo activo ( $c f$. Ef 6, 16-20), oponiéndose a todo tipo de violencia que, a la corta o a la larga, deshumaniza. Por eso, la Iglesia debe ser el lugar en el que se cree -anticipe- este ámbito de paz que excluye la violencia (también la estructural). Asi concretará el mandamiento de Jesús que contiene, en plenitud, la voluntad de Dios: amar al projimo como a uno mismo (cf. Mt 7, 12).

Es desde este estilo de vida - vivido y propuesto como sociedad de contraste en medio del mundo-61, que la Iglesia dará testimonio del proyecto de Jesuís de Nazaret, un testimonio capaz de interpelar y de transformar la sociedad que la rodea.

\section{Notas}

1. "Gott in der Revolution, Evangelische Kommentare 1" (1968) 565-571, condensado en Selocciones de Teologia 8 (1969) 239-248.

2. Según el Informe Especial, aparecido en Inforpress Centroamericane, N2. 931, del 25 de abril de 1991, en 1990, el 80 por ciento de la población de El Salvador viviría en rimación de pobreza (de la cual, el 66 por ciento vivirian en "extrema pobreza") y en Guatemala le proporción serfa del 84 y el 72 por ciento respectivamente.

3. En la base de este artifulo estr una ponencia que diette en septiembre de 1990 , en el Auln Magna de la Universided Pontificia de Salemanca (Espaila), dentro del marco de la reunión anual de la Asociación Biblica Espariola "San Jerónimo". Como el Prof. Espeja habri disertado el dia anterior sobre la satinud de Jesís frente a la violencie, por eso no desarrollo aqui este aspecto. Sobre la actiuid de Juan frente al Esindo, puede consultrse mi articulo "'Mi reino no es de este mundo' (In 18, 36). Conflictivided de la existencis cristima en el mundo según el cuerto evengelio", Extudios Eclesiáricos 54 (1979) 499-525.

4. "Biblia y Fe" 7 (1981) 62. 
5. Aunque esto no vale sólo para el Estado; Juan 11, 49-50 pone el principio de que hay que sacrificar, aunque sea injustamente, los intereses de un individuo a los de la mayoría en boca del sumo sacerdote Caifás.

6. Para entender este aspecto es fundamental la obra de K. Wengsh Pax Romana. Anspruch und Wirklichkeir. Munich 1986, en la que el autor desarrolla ampliamente el teme. Muchas de las cosas que diré en este articulo se inspiran en esta obra.

7. Sobre los logros y los perjuicios que comportaba la Pax Romana, of. Wengst 1. c. 19-71.

8. Cf. Schottroff, citado por Wengsh 1. c. 176, n. 25.

9. De hecho, se reconoce la autridad del estado ( $c f$. $R m$ 13, 1-7; 1P 2, 13-14) y se reza por las autridades paganas ( $c f .1 \operatorname{Tm} 2,1-2)$.

10. Sobre la estructura concéntrica del Apocalipsis y su significado, me parece muy iluminador el art́culo de J. P. Charlier, "El apocalipsis de San Juan. Escritura para el fin de los tiempos o final de las Escrituras?", Selecciones de Teologia 25 (1986) 57 63 (el original aparecí en Lumen Virae 39 (1984) 419-430).

11. El número 7, suma de los números 3 y 4 (como el dace, otro número clave del Apocalipsis, es la multiplicación de 3 por 4), mantiene vivo en la conciencis del lector u oyente del libro que, a pesar de todos los pesares Dios sigue siendo fiel a sus promesas y alianza y que, por lo tart, al final sólo el bien puede triunfar.

12. Hoy es opinión común entre los especialistas que la cifra 666 es una alusión críptica a Domiciano, por cuanto el número equivale a la suma del valor numérico de las letras hebreas que encontramos en la transcripción de las palabras Nerón César.

13. La imagen de la prostitución tiene en los textos bíblicos claramente una connotación religiosa, de abandono del Dios verdadero por entregarse a los f́dolos.

14. Domiciano exigía el culto al emperador y esto era el signo y el distintivo del buen ciudedeno que quería "hacer su vida, hecer carrera", pues era el medio para poder llevar una existencia normal, política y económicamente. Por eso, los cristianos se encontraban con el dilema de que, o bien aceptaban vivir como todo el mundo, rindiendo culo al emperador, o bien rechazaban esta idolatría para vivir fuera de la ley, dispuestos, incluso, al martirio.

15. 1. c. 112.

16. "Otra ceracterística lucana de la manera como los cristianos experimentan la salvación de Dios por medio de Cristo es que viven paclficamente en un mundo romano", The Unity of Luke's Theology, Wilmington, DE 1984, p. 160.

17. lbid., 160 y 166.

18. Ibid., 163.

19. Jbid., 163-166.

20. Cf. Wengst, 112 s.

21. Cf. Wengst, 1. c. 113.

22. Cf. Wengst, 1. c. 114.

23. Cf. Wengst, 1. c. $114 s s$.

24. Cf. Hechos $16,35-40 ; 17,1-9 ; 18,14-15 ; 21,27-40 ; 22,22-29 ; 23,12-34 ; 25,11-12$. 21-25; 26, 32; 27, 1; 28, 30-31 (a peser de estar prisionero en Roma puede evengelizar sin ninguna dificultad!). Cf. también O'Toole, l. c. 163-166.

25. No es casual que estos dos últimos rasgos sean propios de Lucas, como tampoco lo es que en la misma escena del prendimiento tenga también un texto propio en el cual recomienda a sus disclpulos que no utilicen la violencia (cf. 22, 49-51). 
26. Cf. Wengst, 1. c. 131-146.

27. Me refiero a 1Tesalonicenses, 1 y 2 Corintios, Filipenses, Glatas, Romenos y Filenón. En cambio, como ya es sabido, la inagen de Pablo que nos ofrece Hechos es une creación, al menos en parte, lucana y debe ser lelda criticamente desde el punto de vista de la historia

28. Cf. Wengst 1. c. 93-94.

29. Sus adversarios, evidentemente, no lo interpetaben asf (cf. Flp 1, 12-17).

30. Asf lo interpreta tambien Wengst, 1. c. 94.

31. Cf. ibid., 98.

32. Ibid.

33. "Pablo no apuesta por el curso de la historia, por un posible crecimiento hacia la plenitud, sino que espera la salvación de una ruptura defmitiva de la historia, de la venida última de Jesús, definitiva y radicalmente tranformadora del mundo" (Wengath 1. c. 99). Cf. tambien lo que dire más abajo sobre la "reserva escalologice".

34. cf. Wengst, 1. c. 99. Como nota, con razon, E. Tumez, Contra toda condena. La justificación por la fe desde los excluidos. Sen Jose (Costa Rica) 1991, p. 11. n. 38: “As, la consigna 'Paz y seguridad' era para muchos, los dominados y los pobres, une gron mentira, que encubría la injusticia".

35. Aunque el texto no menciona explícitamente a Roms, me parece claro, como indica Wengot, 1. c. 98, que el texto hace alusión a los poderes civiles.

36. Cf. Wengst, 1. c. 99.

37. Así lo interpreta con razón, Wengst 1. c. 97. En la misma línea va W. Schrage, cuando afima: "Pero se ha hecho patente que la función del Estado y de su orden jurfdico no es en absoluto algo que sirva, sin más, a la causa del evangelio $y$ al amor, ni siquiera alll donde el Estado desempeña su misión legitima." (Ethik des Neven Testaments, Gottingen 1982, p. 230). Pero con esto no niego que el acento de 1 Corintios 6, 1ss no estí puesto aquf, sino en que la comunided deberla resolver sus problemas dentro de su ámbito interno, sin necesided de acudir a instancias externas (pagmas).

38. Cf. Wengst, 1. c. 98. De lo contrario, no hubiera sido azotado tres veces, tal como cuenta él mismo en 2 Corintios $11,25$.

39. Cf. Wengst, 1. c. 100.

40. A.l lo ser̂ala, con razón, Schrage, 1. c. 227, al afirmar que el horizonte escatológico (los cristianos tienen su parria y su ciudadanía en el cielo: $f f$. Flp 3, 20) no debe llever al cristiano a saltarse a le torera o a sabotear el orden provisional del Estado con sus obligaciones concretss.

41. Ello implica una nuptura histórica que ha tenido ya su inicio en la muerte y resumección de Cristo.

42. Adl lo ve también Wengst 1. c. 101.

43. Cf. U. Wikkens, Der Brief an die Römer, Einsiedeln y Neukirchen/Vluyn, Vol. III, 1982, Fp. 43ss.

44. Serin una interpolación ulterior, cosa que hoy no suele aceptarse, pues la afirmación crrece de fundamento s6lido: $c f$. Wilckens, 1. c. 30.

45. El texto no tendría especial relevancia para Pablo ni estaria bien inserto an el contexto. Asf, por ejemplo, M. Dibelius Röm 184. Otros autores piensen (cf. Wilckens, 
1. c. 30, n 4) que Pablo ha transmitido aquí "una advertencia tradicional de la parenesis helenístico-judía (...), sin dotarla de un sello particular".

46. Ast lo hace notar Wilckens, 1. c. 30 . Pero con ello no se niega ( $c f$. ibid.) que el fragmento contenga "un tópico de las reglas de conducta común en el cristianismo primitivo" que Pablo ha reproducido a su aire.

47. Dicha exégesis puede verse, por ejemplo, en Wilckens, 1. c. W. i. c. 29-30 estructura así el texto: (a) Tesis (v. 1a). (b) Primer argumento (V. lb-2). (c) Segundo argumento (v. 3-4). (d) Síntesis de (b) y (c) (v. 5)., (e) Tercer agunento (v. 6). (f) Exhortación linal (v. 7).

48. L. C., 226.

49. As[ lo seitalan, con razon Wilckens, 1. c. 34-35; Schrage, 1. c. 227; Wengst 1. c. 104.

50. Asf lo interpreta Wengst, 1. c. 101.

51. cf. Wengst, 1. c. 103-104; Wilckens, 1. c. 34. Con respecto a la sibuación de Pablo se ha sospechado que, dados los problemas que habja tenido hasta entonces con las autoridades romanas, podría temer que él resultase un personaje sospechoso para la comuridad (y autoridades) de Roma: por ello intentaría, con este text, deshacer este posible malentendido o recelo de la comunidad. Con respecto a la comunidad, se ha pensado en que ésta podría correr un cierto peligro de anarquía (cf. Schrage, 1. c. 226), debido a comientes carismáticas o a tendencias celotas ( $c f$. Schrage, ibid.). Pablo, en este caso procuraría contrarrestar estas tendencias (hay, con todo, quien se pregunta si Pablo estaría en situación de poder conocer un bien a la comunidad de Roma; pero, en todo caso, este tipo de problemas eran familiares a un Pablo que estr escribiendo desde Corinto). Otros piensan que el tener que pagar impuestos excesivos habla creado en la comunidad un clima hostil a las autoridades civiles que, a la larga, podía resultar peligroso para la comunidad.

52. Por otro lado, también Romanos 14, 1-15, 13 es una nueva aplicación de la "lógica" cristiana que ha aparecido en Rommos 12-13 a un problema muy especifico, como es el de las relaciones enure los "fuertes" y los "débiles" en la comunidad de Roma

53. Cf. "La logique de Jesus, Romains 5, Enudes théologiques et religieuses 55" (1980) 420-425 (condensado en Selecciones de Teologia 21 (1982) 130-132.

54. Este partir de lo f́́ctico, como don de Dios, me parece un principio paulino que no tiene por qué limitarse al ad istra de la comunidad. También ad extra los dones fácticos por ejemplo los cargos públicos- son para Pablo don de Dios, en-cargos de cara a la sociedad más amplia que constituye el Estado. Con ello no se indica, sin embargo, que para Pablo el modo concreto con que la autoridad civil ejerce su cargo responda, efectivamente, a la voluntad de Dios, de modo que toda "contestación civil" quede excluida.

55. El cristiano es invitado a ser constructor de la paz (cf. Wengst, 1. c. 109) 一 una paz que merezch, de veras, este nombre y que en un mundo tan configurado por la miseria de las mayorias populares y por la violencia estruchral, como lo es, por ejemplo el de El Salvador, suele denominarse una "paz con justicia social".

56. Cf. Wengst, 1. c. 110 (el tipo de armamento que aparece en 1Tesalonicenses 5, 1-11 es defensivo).

57. Cf. Wengst 1. c. 110 (con la n. 121).

58. $C f$. Wengst, 1. c. 111. 
59. 1. c. 36-37. Por eso, E. Kusemann, despues de analizar Romanos 13, llega a la siguiente conclusión: “¿Puede existir una colaboración en la revolución que sea prueba del servicio cristiano a Dios en el mundo? ¿Cúando y donde se da esta posibilided y eato no solo ahora para el ciudadano de una comunided democrática como consecuencin de su responsabilidad polftiea, sino también para equel que, como ciudedmo responsable, quiere a su vez ser tambien cristiano y continuar existiendo como tnl? Mi respuesta personal sería que no se da esta posibilidad más que cuendo los que poseen la autorided política amenazan y destruyen redicalmente esos vínculos que don una coherencie interna a una comunidad política en su conjunto con vistas a un servicio recfproco y la obligan a ello. Cuando no se puede ya servir seriamente al canjunto de une comunidad, sino que eada servicio concreto y realizado en un teremo particular adquiere el carécter de una participación en una destrucción colectiva de sí mismo - ly me parece que esta posibilidad se hizo realided en el tercer Reich, al menos despues de Stalingrado para lodo hombre lúcidol-, entonces no se 1. puede negar al cristiano en cuanto ciudadano el derecho a tomar parte en la revolución. En ln vida cotidiene del mundo la obediencia cristiana recibe su sentido del servicio que podemos y debemos realizar; por eso, en medio de unas condiciones democrticas, puede y debe tambien detenerse all donde, en virtud de la autoridad políica existente, el servicio -que sigue siendo posible en terrenos particularesse hace absolutamente vacío de sentido en el conjunto de la vida de la comunidad" ("Puntos fundamentales para le interpretación de Rom 13", en: Ensayas exegéticos, Solumence 1978, pp. 49-50).

60. No comparto la opinión de Wilckens cuendo dice: "Sin embargo, en el texto de Rm 13, 1-7 no solo no se encuentra ninguna huella de una relativización escatológica del Eatado, sino que la lógica interna del texto excluye incluso tal tipo de relativización" (1. c. 40). Pues, si bien es verdad que el texto aislado de Romanos 13, 1-7 no ofrece ningún indicio que de pie a sefialar la "reserva escatologica", sin enbargo, la cercanfr, en el contexio, de un texto tan significativo, como el que encontramos en Romanos 13, 11-14, obliga a tener en cuenta este trasfondo escatológico que, por otro lado, como el mismo Wilckens reconoce, es túpico de Pablo.

61. Cf. X. Alegre, "La Iglesia que Jesús querla", Diakonia 13 (1989) 223-268, sobre todo 236ss. 